\title{
Defaults, normative anchors, and the occurrence of risky and cautious shifts
}

\author{
Stephan Jagau ${ }^{1,2,3}$ - Theo Offerman ${ }^{1,2}$
}

Published online: 4 July 2018

(C) The Author(s) 2018

\begin{abstract}
Choice shifts occur when individuals advocate a risky (safe) decision when acting as part of a group even though they prefer a safe (risky) decision when acting as individuals. Even though research in psychology and economics has produced a mass of evidence on this puzzling phenomenon, there is no agreement about which mechanism produces choice shifts. In an experiment, we investigate the performance of two prominent mechanisms that have been proposed to explain the phenomenon; (i) rank-dependent utility and (ii) a desire to conform to the wishes of the majority. The evidence provides clear support for the conformity explanation.
\end{abstract}

Keywords Risky shift - Cautious shift - Conformity · Social responsibility · Rank-dependent utility · Peer effects · Group decision making

JEL Classifications D03 - D71 - D81

Electronic supplementary material The online version of this article (https://doi.org/10.1007/s11166-018-9282-6) contains supplementary material, which is available to authorized users.

Stephan Jagau

stephan@jagau.com

1 CREED, University of Amsterdam, Roetersstraat 11, 1018 WB, Amsterdam, Netherlands

2 Tinbergen Institute, Gustav Mahlerplein 117, 1082 MS Amsterdam, Netherlands

3 EpiCenter, Maastricht University, P.O. Box 616, 6200 MD Maastricht, Netherlands 


\section{Introduction}

Many important decisions under risk are taken in small groups. Examples include the investments made in clubs, managing a joint asset portfolio (cf. Barber and Odean 2000), decisions made by a company board or a political committee and the decision of a mountaineering party whether to make the final ascent to the top. It is well-known that in such situations choice shifts may occur. A choice shift happens when individuals advocate a risky (safe) decision when acting as part of a group even though they would prefer a safe (risky) alternative decision when acting as individuals. Although there are many examples of risky and cautious shifts, there is little consensus about the behavioral mechanisms that are driving these shifts.

In this paper, we consider two prominent mechanisms that may systematically produce choice shifts: (i) rank-dependent utility and (ii) conformity. The explanation based on rank-dependent utility focuses on the extra layer of uncertainty when people decide in groups while it abstracts from the social aspect of the situation. In contrast, conformity ignores the uncertainty dimension and zooms in on the social aspect that distinguishes a group decision from an individual decision. In a laboratory experiment, we investigate which of these two explanations correctly predicts when cautious and when risky shifts are observed. To the best of our knowledge, we are the first who distinguish between the two explanations.

Systematic evidence of choice shifts has been reported in psychology since the early sixties (cf. Stoner 1961; Bem et al. 1962; Pruitt 1971; Isenberg 1986). ${ }^{1}$ The prevalence of risky shifts in the early experiments gave rise to diffusion of responsibility theory (Bem et al. 1962, 1964, 1965), which more recently inspired the formal approach of Eliaz et al. (2006) (ERR) based on rank-dependent utility. Diffusion of responsibility theory argues that individuals 'voting' for an outcome in a group might feel less responsible for the outcome than if they directly choose in an individual decision and that this might induce them to push for more risky prospects than they would choose in an individual-decision problem. The psychological cause of this behavior is held to lie in a feeling of disappointment following a failure to realize the good outcome in a risky prospect. When choosing in a group - the argument goes - individuals account less for this potential disappointment since their vote for a prospect matters less for the outcome than their choice in an individual-decision problem would (cf. Pruitt 1971). Starting from Nordhøy (1962) and Stoner (1968), the regular occurrence of cautious shifts in later studies that cannot be accommodated

\footnotetext{
${ }^{1}$ While originally risky shifts were observed much more frequently than cautious shifts, later studies (Stoner 1968; Nordhøy 1962 and many more) gave a more balanced picture. By today's standards, evidence for risky and cautious shifts in these early studies should be taken with a grain of salt since they used choice dilemma questions as stimuli that cannot be unambiguously mapped into the types of decision problems studied in formal decision theory. Studies that have used standard prospects as stimuli were conducted both by psychologists (e.g. Kogan and Zaleska 1969; Pruitt and Teger 1969; Sherman et al. 1968; Davis et al. 1968, 1974; Davis and Johnson 1972; Davis and Hinsz 1982) and economists (e.g. Shupp and Williams 2008; Casari and Zhang 2012; Colombier et al. 2009) and have provided evidence for both types of shifts.
} 
by diffusion of responsibility theory was seen as a strong empirical reason to doubt the validity of this approach.

ERR formalize the intuition behind diffusion of responsibility theory and show how a generalized model based on rank-dependent utility (RDU) preferences can explain risky and cautious shifts. They achieve this by considering the compound lotteries an individual expects to result from the group decision conditional on her own vote as the object of evaluation. These compound lotteries account both for the exogenous risk emanating from the random processes described by the prospects, but also the endogenous risk deriving from other group members' influence on the group decision. E.g., if for a binary group decision between a risky and a safe prospect a person votes for the safe prospect, she effectively chooses a prospect yielding the safe prospect with the probability that the group choice becomes safe if she voted safe and the risky prospect with the probability that the group choice becomes risky if she voted safe. The classical diffusion of responsibility theory ignores this additional layer of uncertainty and implicitly assumes that individuals base their choice on the primitive lotteries presented to the group - even where they do not have full influence regarding the outcome of the group choice.

For an exemplary group-decision problem, we demonstrate that ERR's RDU model accommodates cautious shifts. To see this, suppose an individual expects the safe choice to be implemented with certainty if her decision is not pivotal. This would be the case, for instance, if the decision rule is unanimous decision and the fallback outcome under disagreement is the safe prospect. Then, voting for risky in the group decision generates a compound lottery in which the probability of failing to receive the good outcome of the risky prospect is higher than in the original risky prospect. Now assume the decision maker maximizes RDU preferences with a strictly convex (gain-rank) weighting function such that she overweights probabilities attached to the bad outcomes of a lottery relative to the good outcomes. Then she might well prefer the risky choice if deciding on her own and vote for the safe choice if deciding in the group. The resulting cautious shift in a group decision is in this sense similar to the choice pattern generated in the Allais paradox; both patterns point to a violation of expected-utility theory's independence axiom. ERR show how rank-dependent utility may systematically produce cautious and risky shifts. While their results imply that assuming a certain type of RDU preferences is sufficient for choice shifts in group decisions, similar results can be achieved using other types of preferences outside the RDU class. Recently, Dillenberger and Raymond (2016) have generalized ERR's approach. They show that the choice-shift pattern predicted by ERR is exhibited by a larger class of preferences that includes ERR's RDU preferences, and they provide a set of axioms that is necessary and sufficient for preferences to cause choice shifts in group decisions.

In contrast, a competing explanation for choice shifts that has been developed in psychology assumes that people have a taste for conformity. Asch's line judgments experiments first showed the profound effect that social pressure can have on individuals' reported judgments. This taste for conformity can arise for a number of reasons that will typically lead to different behavioral predictions. In a survey, Cialdini and Goldstein (2004) emphasize two goals that people may implicitly or explicitly pursue when they respond to social pressure. First, people may pursue an 
accuracy goal. That is, when they are unsure of the appropriate choice in a social situation, they may revise their intended choice in the direction of the majority of the group when they are informed of the opinions or choices of other group members. Second, people may care about the outcomes for the others in their group and about how the others judge them. Thus, an affiliation goal may also encourage them to conform to the choices and opinions of others in their group. Nordhøy (1962), Brown (1965), and Stoner (1968) first explained how such social pressure may cause risky and cautious choice shifts. They argue that in a group decision, individual votes get shifted towards the choice that most group members would have preferred in an individual decision. In this approach, choice shifts are conceptualized as a drift towards the ex-ante majority preference. Some studies advocate the affiliation goal that people may pursue when they give in to social pressure (cf. Brown 1965). Other studies favor the accuracy goal (cf. Brown 1965; St. Jean 1970; Stoner 1968; Pruitt and Teger 1967; Vinokur 1971).

Notice that the previously collected evidence in favor of the conformity mechanism does not contradict ERR's RDU theory. ERR predict that if the default in a group is the cautious decision, choice shifts will tend to go in the cautious direction. Likewise, if the default in a group is the risky decision, choice shifts will tend to go in the risky direction. In a group process, the majority position may easily serve as the default which will be implemented if an individual's vote is not pivotal. Thus, the two mechanisms may be quite similar in terms of behavioral patterns that are expected in previous designs.

Our experimental design is the first to allow for a direct comparison of the rank-dependent utility and the conformity explanations for choice shifts. ${ }^{2}$ We use a simplified setup inspired by ERR's model of group processes. This amounts to having our subjects choose between a risky and a safe gamble that, conditional on the treatment, we augment with different layers of a real group decision. One treatment gives ERR's model its best shot. In the group decision of this treatment, subjects are informed of the risky or safe default that will be implemented with exogenous probability, while subjects are not distracted by information about the preferences of their peers and while they also know that their decisions have no consequences for the others. There is also a treatment that gives the conformity approach its best shot. In this treatment, there is no default that causes exogenous uncertainty, while subjects are informed of the preferences of their group members and know that their decisions have payoff consequences for their group members. In between these two extremes, we have some treatments that allow us to systematically study the effect of receiving information regarding the majority preferences, the effect of whether or not the individual decision has payoff externalities to the other group members and the effect of the presence of a default. Thus, a novel feature of our design is that we control the influence an individual's choice has on her final outcome independently of

\footnotetext{
${ }^{2}$ We will not explicitly examine the performance of classical diffusion of responsibility theory but only consider the generalization provided by ERR. ERR's model (and Dillenberger and Raymond's 2016 extension) is the only version of this mechanism to date that accommodates risky and cautious shifts. Since we observe both types of shift in equal proportions (cf. Section 5) any other variant of diffusion of responsibility theory can already be ruled out upon superficial inspection of the data.
} 
social aspects of the choice situation such as the degree of responsibility for others' outcomes and the extent to which subjects learn about others' preferences.

Group discussion is not essential for either of the two mechanisms. To distinguish between the two mechanisms in a clean setting, we do not allow groups in the experiment to explicitly discuss their attitudes toward risk for the specific gambles that they face. $^{3}$ To create a sense of being in a group, our subjects briefly get to know each other before they are informed of the risky decisions that they make. ${ }^{4}$

In agreement with previous work, we find that cautious and risky shifts regularly occur. Our results lend clear support for the conformity mechanism: individuals display a strong tendency to adapt their decisions to the majority preferences in their group. This pattern is strongest when a subject's decision has payoff consequences for other group members - suggesting that choice shifts are partly driven by the activation of the group affiliation goal of the conformity mechanism, or, in economic terms, by other-regarding preferences. Although shifts are common in both directions, we do find an asymmetry in the occurrence of choice shifts when decisions have payoff externalities. A choice shift is particularly likely when a subject exhibits a preference for the risky option when choosing in isolation while she shifts to the cautious option once she is informed that the majority preferred the cautious gamble. ${ }^{5}$

We find only limited support for ERR's approach based on rank-dependent utility. Even in the treatment that gives the theory its best shot, the observed pattern of choice shifts does not agree particularly well with their mechanism; shifts are somewhat more often in the direction of the default (like ERR predict), but the difference is insignificant.

\footnotetext{
${ }^{3}$ Previous studies have found choice shifts when group members have the possibility to communicate (e.g., Sutter 2007, 2009; Baker et al. 2008; Shupp and Williams 2008; Colombier et al. 2009; Casari and Zhang 2012; Bougheas et al. 2013; Harrison et al. 2013). However, choice shifts already robustly occur in group decisions under 'mere exposure' without prior group discussion (Baron and Roper 1976; Blascovich and Ginsburg 1974; Blascovich et al. 1975a, b, 1976; Myers 1978; Myers et al. 1977, 1980; Lahno and Serra-Garcia 2015; Bolton et al. 2015; Eijkelenboom et al. 2018).

${ }^{4} \mathrm{~A}$ different strand of the literature investigates whether decision making becomes more rational when subjects receive information about their peers. Schotter (2003) concludes that decisions in a variety of games with naive advice are closer to the predictions of economic theory than decisions without it. Kocher et al. (2014) find that performance in beauty contest games improves when subjects receive information from peers. Charness et al. (2010) find that subjects perform better in a probability-reasoning task after discussion with fellow subjects. Keck et al. (2014) and Charness et al. (2013) report that decisions are closer to ambiguity neutral when subjects discuss the task with others. Baillon et al. (2016) compare decisions of individuals and small groups under risk across a range of different settings, varying the group decision rule and distinguishing communication and aggregation effects on subjects' behavior. They find that communication effects tend to move group decisions closer to rationality. See Charness and Sutter (2012) for a review and in-depth discussion. Further papers that shed light on risk taking in groups include Cettolin and Tausch (2015), Beckman et al. (2016), and Cettolin et al. (2017).

${ }^{5}$ This asymmetry is reminiscent of Cooper and Rege's (2011) social regret finding. They find that subjects consistently move into the cautious direction when they are provided with information about their peer group. In contrast, we find that the direction of the shift depends on the preferences of the majority in the group. One salient difference between their and our design is that in their design subjects were anonymously assigned to a group. Therefore, subjects were not aware of who would be affected by their decisions, and this may have diminished a desire to conform to the majority.
} 
The only other study that sheds light on the empirical validity of ERR's model is an (unpublished) paper by Gurdal and Miller (2010). In their implementation of the ERR model, the group decision is the risky decision unless all group members vote for the cautious decision. They never provide subjects with information regarding the preferences of the majority. They find that subjects in the group decision tend to shift in the cautious direction even though they should shift in the risky direction if the ERR model drives the choice shift. They favor the explanation that in groups people are affected by a social norm to behave cautiously. An alternative explanation is that subjects implicitly respected other group members' preferences. That is, with unanimous decision making and a risky default, a subject's vote only matters if all the others vote cautiously. Conditional on being pivotal, a voter would know that he imposed the risky lottery on the others who voted cautiously and therefore a desire for conformity with the group preference might make subjects behave more cautiously in the group decision. Gurdal and Miller (2010) do not have observations of group decisions where the default is the cautious decision. Therefore, it is not clear whether subjects become generally more cautious in groups, as Gurdal and Miller (2010) suggest, or whether they move into the direction of the supposed majority preference of the group. Our setup has the advantage of clearly separating between the effects of defaults and information on majority preferences among group members. Possibly as a consequence of this, we find much clearer evidence of choice shifts than Gurdal and Miller (2010). Contrary to Gurdal and Miller (2010), we also find a sizable number of risky shifts, which should not occur if people generally become more cautious when acting in groups.

In this paper we focus on the extent to which rank-dependent utility and conformity contribute to the emergence of choice shifts. There may also be other mechanisms that cause choice shifts. When there are payoff externalities of people's decisions, it may be that individuals change their decisions because they feel responsible for others' outcomes. If such responsibility matters, then in the presence of payoff externalities people may shift their decisions even if they have no information about the majority preference. Charness (2000) reports an effect of social responsibility in a labor market experiment. Charness and Jackson (2009) find that subjects are somewhat more likely to choose the safe option in a stag-hunt game when they are responsible for the payoff of another group member. More closely related are the recent papers by Pahlke et al. (2015) and Vieider et al. (2016) that investigate the role of social responsibility in individual decision making. Social responsibility sometimes leads to less risk taking and sometimes to more risk seeking. Vieider et al. (2016) find that probability weighting becomes more extreme in the presence of social responsibility. 6

The remainder of this paper is structured as follows: Section 2 provides the model that we use and explains how rank-dependent utility may produce choice shifts.

\footnotetext{
${ }^{6}$ Two other lines of research investigate how information aggregation in groups produces collective decisions based on different pieces of private information (cf. Sobel 2014; Bougheas et al. 2015) and how group discussion can shift the collective decision in favor of those individuals that present the most persuasive arguments (cf. Vinokur 1971). Since there is neither private information nor group discussion in our experiment, both of these potentially relevant mechanisms are excluded by construction.
} 
Section 3 describes and motivates the experimental design we used. In Section 4, we show how the design allows us to derive predictions that distinguish the two candidate mechanisms for choice shifts. Section 5 presents the results of our experiment. Section 6 concludes.

\section{Theoretical mechanisms}

In this section, we introduce ERR's model of group decisions and explain how it can produce cautious and risky shifts where diffusion of responsibility theory could only yield risky shifts. ERR argue that, from the participant's point of view, we can decompose any group decision on a binary choice set into an individual decision and a random process as follows: let the choice set $C=\{R, S\}$ be over two finite lotteries, risky $(R)$ and safe $(S)$. To capture the group decision, ERR introduce a pair of probabilities $\mathbf{g}=(a, b)$ where $a \in(0,1)$ is the probability that an individual's vote will be pivotal in the group decision and $b \in[0,1]$ is the probability that the group will choose $S$, conditional on the individual in question not being pivotal. For a given reduced-form group-decision problem $(\mathbf{g}, C), R^{\prime}$ and $S^{\prime}$ represent the compound lotteries if the individual votes for $R$ or $S$, respectively.

Given the reduced-form group decision, the prediction of expected-utility theory is that the preference between $R^{\prime}$ and $S^{\prime}$ is the same as that between $R$ and $S$. The deciding individual should only care about the characteristics of the outcome that she can influence by her decision.

If, however, individuals maximize RDU preferences with a strictly convex (gainrank) weighting function, ERR show that choice shifts will systematically occur. This variant of RDU preferences has been referred to as pessimistic (Wakker 2001a, b) since individuals place excessive decision weights on bad outcomes as compared to the probability weight applied by an expected-utility maximizer. Clearly, this can capture the idea of classical diffusion of responsibility theory where individuals care to avoid the disappointment ensuing after they fail to realize the good outcome of a risky prospect.

The formal result for general binary choices between a prospect $R$ and a degenerate prospect $S$ is given by ERR's theorem 1 which is restated here without proof: 7

Theorem 1 Under rank-dependent utility, the following are equivalent:

1. $\left\{\succsim_{i}\right\}$ exhibits the Allais paradox.

2. For all prospects $R$ and degenerate prospects $S$ and arbitrary $a \in(0,1)$, there exists $b^{*} \in[0,1]$ such that

- $R^{\prime} \succ_{i} S^{\prime}$ if $b<b^{*}$ and $S^{\prime} \succ_{i} R^{\prime}$ if $b>b^{*}$,

- $R \sim_{i} S$ implies $b^{*} \in(0,1)$.

\footnotetext{
${ }^{7}$ As shown in Dillenberger and Raymond (2016), ERR's result can straightforwardly be extended to choices between two non-degenerate lotteries.
} 
We illustrate the theory in a numerical example.

\section{Example 1 (Choice shifts with pessimistic preferences)}

For this example, we assume a preference $\left\{\succsim_{i}\right\}$ represented by Bernoulli-utility function $u=$ id and strictly convex (gain-rank) weighting function $w=(\cdot)^{2}$. Let us consider the prospects $S=5$ and $R=20_{0.5} 0 .{ }^{8}$ We have $20 w(0.5)+[1-w(0.5)] 0=$ $\frac{20}{4}=5$ and thus $R \sim_{i} S$.

Further assume that $i$ faces a family of group-decision problems $\mathbf{g}_{b}=(0.4, b)$. So $i$ 's decision is pivotal with probability $a=0.4$ and if it is not, the group will choose $S$ with probability $b$. The resulting compound lotteries are thus $R_{b}^{\prime}=$ $a R+(1-a)[b S+(1-b) R]$ and $S_{b}^{\prime}=a S+(1-a)[b S+(1-b) R]$. In what follows, we write $r_{y}$ for the (gain rank) of outcome $y$. For example, in prospect $R_{b}^{\prime}$ we have $r_{20}=0.5[a+(1-a)(1-b)]$ and $r_{5}=r_{20}+(1-a) b$. Now let us determine $b^{*} \in(0,1)$ as described in statement (2) above. We start by calculating the utilities of the compound lotteries:

$$
\begin{aligned}
\operatorname{RDU}\left(R_{b}^{\prime}\right)= & 20 w\left(r_{20}\right)+5\left[w\left(r_{5}\right)-w\left(r_{20}\right)\right] \\
= & 20 w(0.5[a+(1-a)(1-b)]) \\
& \quad+5 w([1-a] b+0.5[a+(1-a)(1-b)]) \\
& \quad-5 w(0.5[a+(1-a)(1-b)]) \\
= & 15(0.5[1-0.6 b])^{2}+5(0.6 b+0.5[1-0.6 b])^{2} \\
= & 3.75\left(1-1.2 b+0.36 b^{2}\right)+5\left(0.25+0.3 b+0.09 b^{2}\right) \\
= & 5-3 b+1.8 b^{2}
\end{aligned}
$$

and similarly $\operatorname{RDU}\left(S_{b}^{\prime}\right)=3.8-0.6 b+1.8 b^{2}$. At $b^{*}$ we have $\operatorname{RDU}\left(R_{b^{*}}^{\prime}\right)=$ $\operatorname{RDU}\left(S_{b^{*}}^{\prime}\right)$, such that

$$
\begin{aligned}
5-3 b^{*}+1.8 b^{* 2} & =3.8-0.6 b^{*}+1.8 b^{* 2} \Leftrightarrow \\
b^{*} & =0.5
\end{aligned}
$$

It follows that $i$ displays a risky shift $\left((R \sim S) \wedge\left(R_{b}^{\prime} \succ S_{b}^{\prime}\right)\right)$ for all group-decision problems $\left\{\mathbf{g}_{b}\right\}_{b<b^{*}}$ and a cautious shift $\left((R \sim S) \wedge\left(S_{b}^{\prime} \succ R_{b}^{\prime}\right)\right)$ for all group-decision problems $\left\{\mathbf{g}_{b}\right\}_{b>b^{*}}$.

While the indifference condition in part 2 of Theorem 1 is hard to establish empirically, it is important to realize that it represents only a sufficient (but not a necessary) condition for the occurrence of choice shifts $(b \in(0,1))$. Notably, it is easy to find prospects $R, S$ such that a choice shift occurs for $b^{*} \in(0,1)$ while dropping the indifference condition. A follow-up to the above example illustrates this.

\section{Example 2 (Choice shifts without prior indifference)}

We keep the setup from above, except for setting $R=20_{0.6} 0$. Clearly, $\operatorname{RDU}(R)=$

\footnotetext{
${ }^{8}$ We use Savage's (1954) notational conventions. Hence $X_{p} 0$ is the prospect that yields the amount $X$ with probability $p$ and 0 otherwise.
} 
$7.2>5=\operatorname{RDU}(S)$ such that $R \succ_{i} S$.

For $\mathbf{g}_{b}=(0.4, b)$ as before, the resulting compound lotteries have utilities

$$
\begin{aligned}
\operatorname{RDU}\left(R_{b}^{\prime}\right)= & 20 w(0.6[a+(1-a)(1-b)]) \\
& +5 w([1-a] b+0.6[a+(1-a)(1-b)]) \\
& \quad-5 w(0.6[a+(1-a)(1-b)]) \\
= & 15(0.6[1-0.6 b])^{2}+5(0.6 b+0.6[1-0.6 b])^{2} \\
= & 5.4\left(1-1.2 b+0.36 b^{2}\right)+1.8\left(1+0.8 b+0.16 b^{2}\right) \\
= & 7.2-5.04 b+2.232 b^{2}
\end{aligned}
$$

and similarly $\operatorname{RDU}\left(S_{b}^{\prime}\right)=4.832-2.064 b+2.232 b^{2}$.

At $b^{*}$ we have $\operatorname{RDU}\left(R_{b^{*}}^{\prime}\right)=\operatorname{RDU}\left(S_{b^{*}}^{\prime}\right)$, such that

$$
\begin{aligned}
2.368-2.976 b^{*} & =0 \Leftrightarrow \\
b^{*} & =\frac{74}{93} \approx 0.7957
\end{aligned}
$$

It follows that $i$ displays a cautious $\operatorname{shift}\left((R \succ S) \wedge\left(S_{b}^{\prime} \succ R_{b}^{\prime}\right)\right)$ for all group-decision problems $\left\{\mathbf{g}_{b}\right\}_{b>b^{*}}$.

The reader may verify that if we choose $R=20_{0.4} 0$ (such that $S \succ_{i} R$ ), then $i$ displays a risky shift $\left((S \succ R) \wedge\left(R_{b}^{\prime} \succ S_{b}^{\prime}\right)\right)$ for $b<b^{*}=\frac{1}{7} \approx 0.1429$.

In fact, it can be shown that for every set of prospects $R, S$ such that $R \sim_{i} S$, we can find prospects $\widehat{R}, \widehat{S}$ "close" to $R, S$ such that a choice shift occurs at $\widehat{b} \in(0,1)$ without $\widehat{R} \sim_{i} \widehat{S}$.

\section{Corollary 1}

Assume $\left\{\succsim_{i}\right\}$ satisfies the conditions of Theorem 1. Then, we can find prospects $R, S$ and $b \in(0,1)$ such that $R \succ_{i} S\left(S \succ_{i} R\right)$ and $S_{b}^{\prime} \succ_{i} R_{b}^{\prime}\left(R_{b}^{\prime} \succ_{i} S_{b}^{\prime}\right)$.

Proof In Online Appendix A.

A remaining point of concern is ERR's assumption of pessimistic (i.e. strictly convex) RDU preferences. As follows from the proof of their theorem, both of the above statements are equivalent to the assumption that a studied individual's preference $\left\{\succsim_{i}\right\}$ can be represented by an RDU functional with strictly convex gain-rank weighting function $w$ (probability weighting). Empirical research related to RDU models starting from Baratta and Preston (1948) has shown that the most common (but far from unique) finding is an inverse-S-shaped (gain-rank) weighting function and not a strictly convex one. This variant of RDU preferences departs from pessimism in over-weighting favorable events occurring with small probability. The implication is that ERR's Theorem 1 and the implied comparative statics might hold only in a local version (insofar as the strictly convex regions of the weighting function are decisive for choices). The following numerical example illustrates this. 


\section{Example 3 (Choice shifts with inverse-S-shaped preferences)}

For this example, we assume a preference $\left\{\succsim_{i}\right\}$ represented by Bernoulli-utility function $u=\mathrm{id}$ and (gain-rank) weighting function $w=\left(\exp \left(-1.0467(-\log (\cdot))^{0.65}\right)\right)$. This is the weighting function originally introduced by Prelec (1998) with parameter vector $(\alpha, \beta)=(0.65,1.0467)$. The reader may verify that this specification yields an inverse-S-shaped transformation function with inflection point $\exp (-1) \approx 0.37$ and fixed point close to 0.32 . Wakker (2010, p. 260) argues that this specification captures the empirically-observed inverse-S-shaped weighting functions rather well.

Let us consider the prospects $S_{1}=7, S_{2}=8$ and $R_{1}=35_{0.2} 0, R_{2}=16_{0.6} 0$. Both $C_{1}=\left\{R_{1}, S_{1}\right\}$ and $C_{2}=\left\{R_{2}, S_{2}\right\}$ are choice sets that we used in the experiment. The former choice set is problematic for ERR's model when we assume preferences $\left\{\succsim_{i}\right\}$. Indeed, we will show that, given $\left\{\succsim_{i}\right\}$, a choice shift can occur with $C_{2}$ but not with $C_{1}$.

It is easily derived that

$$
\begin{aligned}
& \operatorname{RDU}\left(R_{1}\right) \approx 8.41>\operatorname{RDU}\left(S_{1}\right)=7 \\
& \operatorname{RDU}\left(R_{2}\right) \approx 8.14>\operatorname{RDU}\left(S_{2}\right)=8
\end{aligned}
$$

We are thus looking for $b_{1}, b_{2} \in[0,1]$ such that $S_{i, b_{i}}^{\prime} \succ R_{i, b_{i}}^{\prime}, i \in\{1,2\}$ (cautious shift). Evaluating the prospects $R_{i, b}^{\prime}, S_{i, b}^{\prime}, i \in\{1,2\}$ with Prelec's function, it can be shown that $\left\{b \mid S_{1, b}^{\prime} \succ R_{1, b}^{\prime}\right\} \cap[0,1]=\varnothing$ and $\left\{b \mid S_{2, b}^{\prime} \succ R_{2, b}^{\prime}\right\} \cap[0,1] \supset[0.52,1]$.

As the example shows, when global strict convexity of $w$ is not satisfied, ERR's Theorem 1 (supplemented by Corollary 1) breaks down as a global result while we may retain it for specific choice sets. For the inverse-S-shaped weighting function considered here, this will be the case for prospects where the upside probability is sufficiently high to make the non-convex region of $w$ irrelevant for the result. ${ }^{9}$

We will explore this issue by studying two types of decision problems (cf. Section 3.1) involving either low or high upside probabilities. Comparing the results for these two types of prospects, we study the extent to which ERR's restrictive assumption of pessimistic preferences is problematic.

Dillenberger and Raymond (2016) further explore the preference foundations of choice shifts ${ }^{10}$ across a range of RDU models and non-RDU models, including Kőszegi and Rabin's (2007) reference dependent preferences. Most notably, they provide necessary and sufficient conditions for preferences to exhibit the pattern from statement 2 of ERR's theorem (where ERR's theorem only gives a sufficient condition). In our experimental test of ERR's model we attempt to induce this pattern in

\footnotetext{
${ }^{9}$ In general, however, relaxing the assumption of a strictly convex $w$-function towards inverse-S-shapes can yield diverse patterns that do not necessarily mirror the one displayed by the Prelec function from Example 2. Take, for instance, the polynomial weighting function $w=3(\cdot)^{3}-4(\cdot)^{2}+2(\cdot)$. This cubic function displays a somewhat more pronounced inverse-S-shape than that from Example 2. The reader may verify that for the prospects from Example 3 we observe a cautious shift at $b \approx 0.9966$ given $C_{1}$, but no choice shift for $C_{2}$.

${ }^{10}$ Dillenberger and Raymond (2016) use the term Consensus Effect to refer to the pattern described by ERR.
} 
Table 1 Part-1 Choice Sets

\begin{tabular}{lllll}
\hline$\#$ & class & $S$ & $R$ & $\mathbb{E}(S)-\mathbb{E}(R)$ \\
\hline 1 & 0 & 7 & $35_{0.2} 0$ & 0 \\
2 & 0 & 7 & $40_{0.2} 0$ & -1 \\
3 & 0 & 7 & $45_{0.2} 0$ & -2 \\
4 & 1 & 8 & $16_{0.55} 0$ & -0.8 \\
5 & 1 & 8 & $16_{0.6} 0$ & -1.6 \\
6 & 1 & 8 & $16_{0.65} 0$ & -2.4 \\
\hline
\end{tabular}

the lab for the two extreme cases where $b \in\{0,1\}$ (cf. Section 4). Our results are therefore equally fit to shed light on the more general types of preferences examined in this more recent contribution.

\section{Experiment}

The computerized experiment was run at CREED, the Economics laboratory of the University of Amsterdam. Subjects read the instructions of the experiment at their own pace on screen (see Online Appendix C). They had to correctly answer some control questions testing their understanding before they could continue with the experiment. Most sessions were run with 20 subjects. We ran 15 sessions with a total of 280 subjects. Subjects received a 5 euro show-up fee and earned on average an additional 8.5 euro with their choices (minimum 0 euro, maximum 45 euro). Each subject participated in only one of the 5 treatments.

Each session of each treatment was divided into three stages: a preliminary communication stage, the individual-decision part of the experiment (part 1), and the group-decision part of the experiment (part 2). ${ }^{11}$ The instructions were communicated in parts; subjects only received the instructions for a stage after a previous stage had been completed. There was no difference in the experimental design of the first two stages. The treatments only differ in how the group-decision part was shaped.

At the start of the session, subjects were randomly assigned to workplaces in the laboratory. Each subject was assigned to a group of 5 individuals that were seated nearby each other. We decided to have a group size of 5 instead of 3 to have enough chance of preference heterogeneity as would be needed to test the theories. Every subject was informed that at the end of the experiment only one of the choice problems from part 1 and part 2 would be randomly selected and used for payment. In addition, subjects were made aware that the payoff for a part-2 problem might be affected by other group members' decisions and that their decision for a part2 problem might similarly affect the payoffs for other group members. There were visual barriers between tables and verbal communication during the session was not

\footnotetext{
${ }^{11}$ We did not run the reverse setup in which participants first face a group-decision stage and then an individual-decision stage because this order would be logically impossible in the treatments where we provide information about the majority preferences.
} 
Table 2 Overview of Treatments

\begin{tabular}{lllll}
\hline Treatment & Default & Majority-Info & Payoff-Externality & \# Subjects \\
\hline Def-NoMaj-NoExt & Yes & No & No & 55 \\
Def-Maj-NoExt & Yes & Yes & No & 55 \\
NoDef-Maj-NoExt & No & Yes & No & 60 \\
Def-Maj-Ext & Yes & Yes & Yes & 50 \\
NoDef-Maj-Ext & No & Yes & Yes & 60 \\
\hline
\end{tabular}

allowed. In the first stage, the experimenter invited subjects to stand up in order to freely look at the other members of their group over the barriers. Thereafter, the members of each group were invited to have an unstructured 3-minute conversation via chatboxes. We added this feature to the experiment to emphasize that subjects were part of an actual group. When subjects' decisions matter for other group members' payoffs, we think that it is natural and important that they know who will actually be affected.

In the individual-decision part of the experiment, subjects were presented with 6 binary choice sets, each containing a "safe" prospect $S$ and a "risky" alternative prospect R. The choice sets we used are shown in Table 1. We use Savage's (1954) notational conventions. I.e., $X_{p} 0$ is the prospect that yields the amount $X$ with probability $p$ and 0 otherwise. There were two classes of choice sets. In the first class, the risky prospect featured a low probability of winning a high amount. In the second class, the risky prospect featured a high probability of winning a moderate amount. Choice sets were presented one after another and the order of presentation was the same for all subjects. For each choice set, a subject made an irrevocable choice before she continued with the next choice set. The goal of this part was to elicit subjects' individual preferences over the relevant prospects.

The group-decision part differed across treatments along three dimensions: 1 . whether or not a default was present; 2 . whether or not information about the majority choice in part 1 in the group was provided and 3. whether or not a subject's decision had payoff consequences for the others in the group. The main features and names of the treatments are summarized in Table 2.

In the three treatments with a default, subjects were presented with 12 choice problems that were based on the ones from part 1 in the following way. For a given choice set $\{\mathrm{R}, \mathrm{S}\}$ from part 1 a default outcome $\mathrm{D}$ in $\{\mathrm{R}, \mathrm{S}\}$ was pre-selected. Subjects would receive the default outcome with $60 \%$ probability, no matter what they chose. This corresponds to ERR's non-pivotal case. Subjects were asked to choose to stay with the default or to deviate from the default. A choice to deviate would be implemented with the residual $40 \%$ probability and corresponds to ERR's pivotal case. ${ }^{12}$

\footnotetext{
${ }^{12}$ We thus set $a=0.4$ in terms of the reduced-form problem described by $\mathbf{g}$ (cf. Section 2). We chose a probability below $50 \%$ to capture the fact that no member of a five-person group can a priori be expected to have a decisive influence on the outcome of the decision. At the same time, we set it close to $50 \%$ to make decision makers care about their choice.
} 

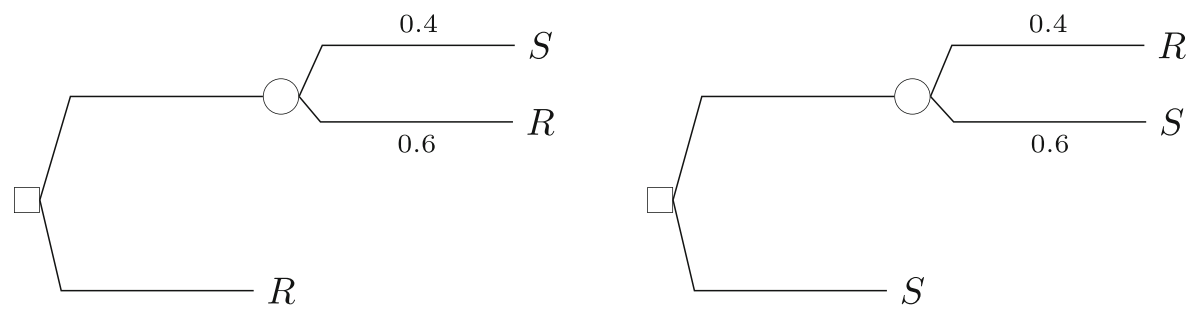

Fig. 1 Reduced-form models for $\mathbf{g}=(0.4,0)$ (Left) and $\mathbf{g}=(0.4,1)$ (Right)

So subjects effectively chose out of sets $\{0.4 R+0.6 D, 0.4 S+0.6 D\}, D \in\{R, S\}$ in this part. For each problem, subjects were informed about the default prior to making a decision. Each choice problem of part 1 was offered twice, once with the risky prospect as default and once with the safe prospect as default (cf. Fig. 1 for decision trees illustrating our part-2 problems with default). In the treatments without a default, subjects were presented with 6 choice problems that in terms of prospects were the same as the ones of part 1 .

There was one treatment where we did not provide subjects with the information about the preferences of the majority in their group: Def-NoMaj-NoExt. In this treatment, subjects' decisions could not affect the payoff of other group members. ${ }^{13}$ This treatment gave the best shot to the theory of ERR, because it excluded potentially confounding motivations such as a desire to conform to the majority preference or a desire to provide others with the prospect that they preferred. ${ }^{14}$

In all 4 other treatments, we did provide subjects with information about the majority choice in their group for the corresponding part-1 problem. Specifically, before they made their choice, subjects were either informed that the default choice coincided with the majority choice of their group for the corresponding part-1 problem or, if this was not the case, that it coincided with the minority choice. In the treatments that provided information about the majority choice, we had a full $2 \times 2$ design in which we systematically varied the presence of the default and the presence of the payoff externality on the other group members.

In this paper we focused on the treatments that are most interesting to distinguish between the roles that conformity and ERR's theory play in explaining choice shifts. The left-out treatments would have been helpful to answer some adjacent questions.

\footnotetext{
${ }^{13}$ All this implies that the 'group decisions' in Def-NoMaj-NoExt are actually individual decision problems with a more complicated decision tree that should bring the mechanism advocated by ERR into play. Cf. Section 4 for details.

${ }^{14}$ In the treatments with a default, the order of presentation was randomized for each group as follows. We randomly picked one of the two classes of problems from part 1, each containing 3 choice sets. We then randomly determined a default for these three choice sets and presented the three resulting part-2 problems to the subjects. All problems from the other class were presented to subjects with randomly fixed defaults. We then presented the three problems with which they started but now with the other default. We ended with the three problems from the second block but now with the other default. For treatments without default, we randomized the order in which the prospects classes were presented across groups.
} 
For instance, in the treatment NoDef-NoMaj-NoExt the decision problems in stage 1 and stage 2 would be identical. So conducting this treatment would tell us to what degree subjects randomly reverse their preferences between prospects. The other two left-out treatments we did not run because the absence of majority choice information implies that conformity does not predict anything. Still these treatments may be interesting to shed light on whether responsibility plays an independent role in explaining choice shifts. We come back to this possibility in Section 6.

In the treatments without payoff externality, subjects knew that their own decision only affected their own payoff. Here, the choices that subjects made in part 2 were never communicated to other subjects. Subjects were made aware of these facts at the start of part 2. In the two treatments with a payoff externality, one individual's choice became the choice for all members in the group. That is, if the payoff-relevant problem ex post turned out to belong to part 2, one group member's decision was selected at random to determine the payoff for all members. Each member's decision had an equal chance of being selected to matter on a given part-2 problem. If a subject's decision was implemented for the group, the identity and the decision of the subject were revealed to everyone in the group. Subjects were made aware of these facts in the instructions for part 2.

\subsection{Gambles \& payment}

Each problem had an equal probability of being selected for payment and we selected the same problem for each group. For all problems with a pivotal player, one individual per group was selected to be pivotal with all members having equal probability. For all problems with default we made one random draw per group to decide if subjects' decisions would count or if the default would be implemented. Lastly, we played out the risky lottery one time for each group. All random draws used to determine the payments were computerized and visualized on screen for the concerned subjects.

The incentive compatibility of a randomized incentive scheme may be questioned if subjects choose in accordance with rank-dependent utility like advocated by ERR (cf. Holt 1986). Since rank-dependent utility violates Savage's sure-thing principle, the extent to which subjects reduce or do not reduce compound lotteries matters for behavior. This does not mean that RDU preferences necessarily imply that randomized incentive schemes are not incentive compatible (cf. Cohen et al. 1987; Bardsley et al. 2009). Specifically, the common assumption that behavior of a subject is independent across different decision problems will continue to hold with RDU preferences under the so-called isolation assumption (Kahneman and Tversky 1979). That is, we must assume that subjects consider the decision trees at all decision problems in the experiment in isolation from each other. For standard applications of the randomized incentive scheme in which one randomly-selected decision per player becomes payoff-relevant, there is an extensive empirical literature on this issue, starting with Cohen et al. (1987), Starmer and Sugden (1991), and Cubitt et al. (1998). Most studies, including these seminal contributions, report evidence in favor of the isolation assumption (cf. Hey and Lee 2005a, b; Laury 2005; Lee 2008) albeit the 
occasional negative result has also been presented (cf. Cox et al. 2014; Harrison and Swarthout 2014). The consensus in the field is that experimental subjects choose in accordance with the isolation assumption such that the use of a standard randomized incentive scheme is unproblematic for studies of RDU models. More importantly, our subjects received the choice problems one at a time, without information regarding the future choice problems, and without the possibility of revising the previous choices. Therefore, it was impossible for them to integrate all choices into one big decision problem. The design made it practically impossible to deviate from the isolation assumption.

Our treatments Def-Maj-Ext and NoDef-Maj-Ext introduce another layer of randomization. A pivotal subject is selected at random and that subject's decision is implemented for the whole group. This incentive system is very close to the betweensubject randomized incentive scheme where only some randomly selected subjects get paid for their choices in a given experimental session. This method has also been frequently used across a range of different setups (cf. Cohen et al. 1987; Camerer and Ho 1994; Abdellaoui et al. 2008, 2011, 2013a, b; Andersen et al. 2008; Burks et al. 2009; Toubia et al. 2012). In the studies where an explicit comparison to other incentive schemes was made no differences in behavior have been found for simple choice tasks as used in our experiment (cf. Tversky and Kahneman 1981; Bolle 1990; Cubitt et al. 1998; Armantier 2006; Schunk and Betsch 2006; Harrison et al. 2007; von Gaudecker et al. 2011; Baltussen et al. 2012). Charness et al. (2016) provide an in-depth methodological discussion and offer support for paying only a subset of the decisions.

When designing the prospects (reported in Table 1), we had two goals in mind. First, we wanted to construct choice sets where subjects would be close to indifferent between the two prospects. The reason is that both theoretical mechanisms that we test in our paper predict that choice shifts occur primarily in situations of near-indifference. When one prospect is much better than the other, all group members may agree on the same prospect when choosing individually, which preempts a potential choice shift of the minority to the majority. When people prefer to conform to the majority, there is larger potential for choice shifts if the minority is larger. At the same time, rank-dependent utility in combination with pessimistic probability weights will only yield choice shifts when a decision maker is not too far from indifference when choosing individually.

Second, to shed more light on ERR's theory, we wanted to have observations of behavior in choice sets where the risky prospect has a large probability of a good outcome as well as observations of behavior where the risky prospect gives a small probability on a very good outcome. For lotteries featuring a rather small probability of winning a high amount relative to the prospect's expected value, subjects in previous studies have displayed a tendency to overweight these small probabilities attached to good outcomes (cf. Kunreuther and Pauly 2004; Harbaugh et al. 2010). This is essentially a manifestation of the inverse-S-shaped weighting functions that are often reported in the literature. The theory of ERR assumes a pessimistic probability weighting function and may fail if subjects overweight small probabilities of the good outcome. It may be that the conditions required by ERR's theory are 
fulfilled for risky prospects with a large probability of the good outcome but not for risky prospects with a small probability of the good outcome. Our design allows us to investigate whether ERR's theory performs better for choice sets that include a high-probability risky prospect.

\section{Predictions}

Our design in part 2 implements a special case of ERR's reduced-form model $(\mathbf{g}, C)$. To see this, take $a=0.4$ and $b \in\{0,1\}$ to generate the decisions trees shown in Fig. 1 that were implemented in our treatments with a default. Here the studied individual's decision is pivotal with probability 0.4 and otherwise (i.e. with probability 0.6 ) the default choice of either $S$ or $R$ is implemented with certainty. The left side of the figure displays the decision tree of our part-2 problems with a safe default; the right side presents the part- 2 problems with a risky default.

While the resulting decision problems are essentially individual-decision problems, a decision maker in ERR's framework would perceive them as equivalent to a group decision under a unanimous decision rule and with the default as the disagreement outcome. The equivalence is easily seen as follows: assume that a group chooses from a binary set of prospects $C=\{R, S\}$ (as described in Section 2) by unanimity ruling and that a predetermined default outcome $D \in\{R, S\}$ is implemented if there is no unanimous vote. Then the reduced-form model of the decision situation from the perspective of a given group member looks as follows: Either there is unanimous agreement to depart from $D$ among the other group members and the individual's vote is decisive for the outcome. Or there is no unanimous agreement among the other group members in which case the outcome will be $D$ irrespective of what the studied individual does. So unanimous decision maps into the special case of ERR's model where either the individual's decision is pivotal or otherwise one of the primitive prospects $R$ and $S$ (the default) will be implemented with certainty. We thus have the reduced-form group decisions $\mathbf{g}$ with $b \in\{0,1\}$ where $b=0$ if $D=R$ and $b=1$ if $D=S$.

ERR's theorem 1 predicts a clear pattern in the choice shifts that may be observed for the problems $\mathbf{g}=(0.4,0)$ and $\mathbf{g}=(0.4,1)$.

- If the default is $R$ (such that $b=0$ ), then any observed choice shift will be a shift from $S$ to $R$ (risky shift).

- If the default is $S$ (such that $b=1$ ), then any observed choice shift will be a shift from $R$ to $S$ (cautious shift).

So the clear-cut prediction of ERR's model is that choice shifts in our experiment are possible only in the treatments with default and that they will go in the direction of the default choice $D$.

The conformity mechanism (cf. Section 1) predicts a different pattern. In this approach, a clear pattern of choice shifts is possible in the treatments when individuals are provided information about the majority choice among members of their group for the corresponding part-1 problem. The information about the majority choice 
may serve as an anchor that makes subjects in the minority change their mind. The conformity mechanism then makes the following simple prediction:

- If the majority choice on a part-1 problem was $R$, then any observed choice shifts on the corresponding part-2 problems should go from $S$ to $R$ (risky shift).

- If the majority choice on a part-1 problem was $S$, then any observed choice shifts on the corresponding part-2 problems should go from $R$ to $S$ (cautious shift).

In the informational or accuracy-driven version of the conformity mechanism according to which choice shifts are driven by a conformist revision of individual preferences, shifts should always go towards the part-1 majority preference for subjects independent of whether choices have a payoff externality on others in the group or not. Another possibility is that the conformity mechanism as based on other-regarding preferences applies (see Section 1 above). That is, it could be that individuals in a group move in the direction of the majority preference because they care about the externalities that their decision has on others' payoffs. If otherregarding preferences drive the conformity mechanism, choice shifts should only be observed when decisions have payoff externalities for others.

\section{Results}

In the analysis, we take the subject as the unit of analysis. For each subject, we calculate the number of actual shifts in a certain direction (for instance in the direction of the majority choice) as a percentage of the number of cases in which this particular shift was possible, and we compare it to the number of actual shifts in the opposite direction, as a percentage of the number of cases in which the opposite shift was possible (in the example in the direction of the minority choice). Therefore, in the statistical tests, each subject gives us one paired observation at most. In some cases, a subject does not give us a paired data point. For instance when a subject in part 1 always chooses in agreement with the majority, we cannot calculate how often this subject shifts when her position agrees with the minority. Therefore, we always report sample sizes for the conducted statistical tests. We use non-parametric tests to investigate whether differences are statistically meaningful. ${ }^{15}$

Overall, choice shifts are a quite common phenomenon in our experiment. Aggregated across treatments, we observe choice shifts in $24 \%$ of the possible cases. Turning to risky and cautious shifts, a general point distinguishing Eliaz et al. (2006) from the early psychological research on choice shifts (cf. Stoner 1961; Bem et al. $1962,1964,1965)$ is that risky shifts are not in general supposed to occur more

\footnotetext{
${ }^{15}$ Since subjects in a given group chatted only among themselves and received the same group-specific information about part-1 majority preferences, the part-2 problems might be held to systematically differ across groups in the treatments with majority-choice information. To account for this potential confound, we correct the Wilcoxon tests that we use throughout the empirical analysis for clustering at the group level. This is achieved by calculating the standard test statistics for pairs of groups and then performing the respective test on population averages of these statistics. The sampling distributions of these adjusted statistics are estimated using bootstrapping techniques.
} 
Table 3 Shifts and Defaults

\begin{tabular}{|c|c|c|c|c|c|}
\hline & & Towards Default $^{1}$ & Against Default ${ }^{1}$ & $p^{2}$ & $n$ \\
\hline \multirow[t]{3}{*}{ Total } & Shift & $26.6 \%$ & $24.4 \%$ & 0.356 & 55 \\
\hline & Risky Shift & $25.8 \%$ & $18.0 \%$ & 0.024 & 51 \\
\hline & Cautious Shift & $34.8 \%$ & $36.5 \%$ & 0.729 & 45 \\
\hline \multirow[t]{3}{*}{ High Probability } & Shift & $29.7 \%$ & $25.5 \%$ & 0.414 & 55 \\
\hline & Risky Shift & $35.8 \%$ & $24.0 \%$ & 0.177 & 34 \\
\hline & Cautious Shift & $30.3 \%$ & $35.2 \%$ & 0.216 & 44 \\
\hline \multirow[t]{3}{*}{ Low Probability } & Shift & $25.5 \%$ & $23.0 \%$ & 0.424 & 55 \\
\hline & Risky Shift & $21.4 \%$ & $15.2 \%$ & 0.203 & 46 \\
\hline & Cautious Shift & $40.0 \%$ & $39.3 \%$ & 0.835 & 25 \\
\hline
\end{tabular}

Data from treatment Def-NoMaj-NoExt (55 Subjects)

${ }^{1}$ Mean observed frequency of choice shifts (observed shifts in $\%$ of possible cases)

${ }^{2}$ Wilcoxon signed-rank test; frequency of shifts towards vs. against default

frequently than cautious shifts. Both risky and cautious shifts are very common in our experiment. Risky shifts occur in $21 \%$ of the possible cases and cautious shifts in $28 \%$ of the possible cases. Comparing the propensities of subjects to make risky and cautious shifts in a Wilcoxon signed-rank test, we find no significant difference at the subject level. ${ }^{16}$

We first investigate the possibility that rank-dependent utility causes choice shifts in the treatment that gives ERR's theory its best shot. In Def-NoMaj-NoExt, subjects are not distracted by information of the majority choice or the possibility that their choice affects the payoffs of other group members. The top panel of Table 3 presents the mean frequencies of shifts towards and against the default. Overall, choice shifts are somewhat more often in the direction of the default, but the modest difference is not significant at the $10 \%$ level. While cautious shifts are completely independent of the default, the difference between risky shifts towards and against the default is significant at the $5 \%$ level.

If subjects choose in accordance with an inverse-S weighting function instead of a pessimistic weighting function, ERR's pattern of choice shifts could be observed for the high-probability lotteries but not for the low-probability lotteries. The lower panels of Table 3 address this possibility. Indeed, shifts towards the default instead of against the default are somewhat more common in the high-probability lotteries than

\footnotetext{
${ }^{16}$ Given that cautious shifts are somewhat more common than risky shifts, it is interesting to examine whether there is a significant shift to risk aversion as subjects move from part 1 to part 2 . Given that the risky prospect has a (weakly) higher expected value than the safe one in all of our decision problems, the number of times that the safe prospect was chosen by a subject can be used as a measure of risk aversion. Comparing the frequency of risky choices in part 1 and part 2 of the experiment at the subject level, we do not find a significant difference $(\mathrm{p}=0.378, \mathrm{n}=280)$. The result turns out to be robust across our different treatments.
} 
Table 4 Shifts at Minority and Majority Positions

\begin{tabular}{llllll}
\hline & & At Minority & At Majority & $p^{2}$ & $n$ \\
\hline No Externality & Shift & $42.1 \%$ & $14.4 \%$ & 0.001 & 43 \\
& Risky Shift & $47.5 \%$ & $17.5 \%$ & 0.103 & 21 \\
& Cautious Shift & $34.1 \%$ & $11.4 \%$ & 0.029 & 22 \\
Externality & & & & \\
& Shift & $52.9 \%$ & $14.5 \%$ & 0.000 & 47 \\
& Risky Shift & $36.7 \%$ & $12.8 \%$ & 0.038 & 22 \\
& Cautious Shift & $67.0 \%$ & $17.2 \%$ & 0.008 & 24 \\
\hline
\end{tabular}

Data from treatment NoDef-Maj-NoExt (60 Subjects)

${ }^{1}$ Mean observed frequency of choice shifts (observed shifts in $\%$ of possible cases)

${ }^{2}$ Wilcoxon signed-rank test; frequency of shifts at minority vs. at majority position

in the low-probability lotteries, but in both cases the difference remains insignificant. For both high- and low-probability lotteries, risky shifts are somewhat more likely to occur in the direction of the default. But unlike when we aggregate over lottery types, the difference is insignificant here. Again, cautious shifts seem to occur completely independent of the default. Overall, this treatment provides only limited support for ERR's theory.

Next we zoom in on the occurrence of choice shifts in the treatments that provide the best shot for the conformity mechanism. That is, we look at the treatments NoDef-Maj-NoExt and NoDef-Maj-Ext in which the subjects were not potentially distracted by a default in the group choices. Table 4 presents the results for these treatments. In agreement with the conformity mechanism, subjects in the minority position frequently move into the direction of the majority position. The differences are substantial and significant, and the effect sizes are huge compared to what we observed in the treatment that focused on ERR's theory (cf. Table 3). Even though the results appear to be more accentuated when subjects' decisions have consequences for the payoffs of the other group members, the data without such externalities also agree with the conformity mechanism to a remarkable extent. Overall, our subjects display a strong desire to conform to the majority. Interestingly, subjects who found themselves to be part of the minority when they chose the risky lottery in part 1 are very likely to shift to the cautious choice in the group decision when there are externalities on others' payoffs. At the same time, in the settings without externalities the more common pattern is that minority individuals who chose the safe lottery will shift to the risky one. We lack sufficient observations to compare shifting propensities for cautious and risky shifts in the minority position (the sample of individuals who made both a risky minority choice and a cautious minority choice is very small). However, comparing propensities to shift cautiously and riskily across both minority and majority positions, we find no significant difference for either treatment.

In our treatments Def-Maj-NoExt and Def-Maj-Ext, we investigate what happens when subjects have the possibility to move in the direction of the default as well as in 
Table 5 Shifts, Defaults and Minority/Majority Positions

\begin{tabular}{lllll}
\hline & Shift to default $^{1}$ & Shift against default & $p^{2}$ & $n$ \\
\hline At Minority Position & $36.8 \%$ & $35.7 \%$ & 0.583 & 79 \\
At Majority Position & $22.9 \%$ & $15.9 \%$ & 0.012 & 105 \\
$p^{3}$ & 0.044 & 0.002 & & \\
$n$ & 79 & 79 & & \\
\hline
\end{tabular}

Data from treatments Def-Maj-NoExt and Def-Maj-Ext (105 subjects)

${ }^{1}$ Mean observed frequency of choice shifts (observed shifts in $\%$ of possible cases)

${ }^{2}$ Wilcoxon signed-rank test; frequency of shifts towards vs. against default

${ }^{3}$ Wilcoxon signed-rank test; frequency of shifts at minority vs. majority position

the direction of the majority. The results are shown in Table 5. On the main diagonal we report about the cases that agree or disagree with both theories. That is, these cells present the common cases where a subject in the minority position shifts to the default and the rare cases where a subject in the majority position shifts against the default. The numbers off the main diagonal are most interesting, because they represent the cases where the theories make competing predictions. In conflicting cases, subjects shift significantly more often in the direction predicted by the conformity mechanism $(35.7 \%)$ than in the direction of the default $(22.9 \%),(p=0.037, n=79)$. Notice further that for subjects in the minority position, the default is inconsequential in their decision to shift. In contrast, when subjects in the majority position shift, it is significantly more often in the direction of the default than against the default. So ERR's theory is able to pick up this secondary effect.

In Table 6, we provide further evidence for the role that payoff externalities play in the propensity of subjects to shift. The table combines the data of all four treatments that provide subjects with information about the majority position. The presence of payoff externalities for the group members roughly doubles the gap between shifts at

Table 6 Shifts and Externalities

\begin{tabular}{lllll}
\hline & No externality & Externality & $p^{2}$ & $n$ \\
\hline Shift & $17.2 \%$ & $34.6 \%$ & 0.006 & 169 \\
Risky Shift & $16.0 \%$ & $26.3 \%$ & 0.112 & 75 \\
Cautious Shift & $22.8 \%$ & $42.0 \%$ & 0.046 & 92 \\
\hline
\end{tabular}

Data from treatments NoDef-Maj-NoExt, NoDef-Maj-Ext, Def-Maj-NoExt, and Def-Maj-Ext (225 subjects)

${ }^{1}$ Mean observed difference in frequency of choice shifts (observed shifts in $\%$ of possible cases) at minority and majority position

${ }^{2}$ Wilcoxon rank-sum test; difference in frequency of shifts at minority and at majority position, externality vs. no externality 
Table 7 Shifts and Gender

\begin{tabular}{|c|c|c|c|c|c|}
\hline & & Male $^{1}$ & Female $^{1}$ & $p^{2}$ & $n$ \\
\hline \multirow[t]{3}{*}{ Total } & Shift & $18.8 \%$ & $27.1 \%$ & 0.001 & 225 \\
\hline & Risky Shift & $17.9 \%$ & $25.1 \%$ & 0.017 & 203 \\
\hline & Cautious Shift & $21.0 \%$ & $31.2 \%$ & 0.002 & 190 \\
\hline \multirow[t]{3}{*}{ At Minority } & Shift & $31.8 \%$ & $53.2 \%$ & 0.000 & 169 \\
\hline & Risky Shift & $29.8 \%$ & $43.4 \%$ & 0.110 & 78 \\
\hline & Cautious Shift & $31.5 \%$ & $64.4 \%$ & 0.000 & 104 \\
\hline \multirow[t]{3}{*}{ At Majority } & Shift & $14.2 \%$ & $19.4 \%$ & 0.030 & 225 \\
\hline & Risky Shift & $15.3 \%$ & $20.9 \%$ & 0.074 & 200 \\
\hline & Cautious Shift & $16.8 \%$ & $18.6 \%$ & 0.293 & 178 \\
\hline \multicolumn{6}{|l|}{ No Externality } \\
\hline \multirow[t]{3}{*}{ At Minority } & Shift & $27.5 \%$ & $46.8 \%$ & 0.006 & 86 \\
\hline & Risky Shift & $30.1 \%$ & $43.7 \%$ & 0.214 & 41 \\
\hline & Cautious Shift & $23.0 \%$ & $50.2 \%$ & 0.027 & 52 \\
\hline \multirow[t]{3}{*}{ At Majority } & Shift & $14.0 \%$ & $23.0 \%$ & 0.000 & 115 \\
\hline & Risky Shift & $15.9 \%$ & $26.3 \%$ & 0.000 & 105 \\
\hline & Cautious Shift & $18.3 \%$ & $17.9 \%$ & 0.610 & 100 \\
\hline \multicolumn{6}{|l|}{ Externality } \\
\hline \multirow[t]{3}{*}{ At Minority } & Shift & $36.1 \%$ & $60.1 \%$ & 0.001 & 83 \\
\hline & Risky Shift & $29.4 \%$ & $43.2 \%$ & 0.345 & 37 \\
\hline & Cautious Shift & $39.3 \%$ & $80.7 \%$ & 0.000 & 52 \\
\hline \multirow[t]{3}{*}{ At Majority } & Shift & $15.5 \%$ & $14.5 \%$ & 0.757 & 110 \\
\hline & Risky Shift & $14.5 \%$ & $15.3 \%$ & 0.920 & 95 \\
\hline & Cautious Shift & $14.8 \%$ & $19.5 \%$ & 0.306 & 78 \\
\hline
\end{tabular}

Data from treatments NoDef-Maj-NoExt, NoDef-Maj-Ext, Def-Maj-NoExt, and Def-Maj-Ext (225 subjects) ${ }^{1}$ Mean observed frequency of choice shifts (observed shifts in $\%$ of possible cases)

${ }^{2}$ Wilcoxon rank-sum test; frequency of shifts, female vs. male

the minority and shifts at the majority position. ${ }^{17}$ This treatment effect seems to be driven by cautious shifts in particular.

Finally, Table 7 presents a remarkable but unanticipated gender effect in our data. Overall, it appears that women are more likely to shift than men. Especially when they are in a minority position, women are much more likely to shift than men are.

\footnotetext{
${ }^{17}$ The gap between shifts at minority position and at majority position across treatments is a meaningful indicator of a potential treatment effect since we observe shifts at minority position to be more frequent than shifts at majority position across the board.
} 
The lower parts of the table break down the gender effect for whether or not the subject's decision has payoff externalities. Interestingly, even in the absence of payoff externalities, there is already a sizable gender effect. This result suggests that women are less sure of their preferences over risky options. If anything, the gender difference is more pronounced when subjects' decisions also determine the payoffs of the others in their group, which suggests that women are also more group-oriented than men. Surprisingly, women are also more likely to shift when they are in the majority position. This finding points to the possibility that women are generally less consistent in their choices than men. The difference in shifts between the genders at the majority position is much smaller than the difference in shifts at the minority position though, so it is not the case that the complete gender effect can be attributed to women being less consistent. Our results suggest that women have a stronger desire than men to conform to the majority, and that this effect is to a large extent due to women being less sure of their preferences. ${ }^{18}$

\section{Conclusion}

This study experimentally compared two prominent explanations of choice shifts in groups. One contestant was the conformity mechanism that traces shifts from individual decision to votes in group decisions to the influence of a social norm on behavior in the group setting. The other was Eliaz et al.'s (2006) approach based on rank-dependent utility that operates entirely on individual risk preferences.

We find very clear signs that conformity matters. Already when only information on majority choices is provided and individuals make choices on their own behalf only, we find a strong and significant conformist influence (Table 3). This adds to previous evidence regarding direct effects of peer information on choices under risk (cf. Cooper and Rege 2011; Lahno and Serra-Garcia 2015; Goeree and Yariv 2015). Combining information about others' preferences with responsibility for these other subjects' payoffs makes decision makers take others' preferences into account more than they do if the decision is on their own behalf only. When subjects' decisions also determine the payoffs of others, we again find strong evidence that subjects shift in the direction that is preferred by the majority. So it is not the case that we always find a shift towards the cautious choice when subjects are responsible for the payoffs of others, as might be conjectured on the basis of Charness and Jackson (2009).

\footnotetext{
${ }^{18}$ Another potentially interesting exercise is to examine whether the occurrence of choice shifts in the group-decision part correlates with violations of expected-utility theory in the individual-decision part. In our design, the only violation that can be observed in the individual-decision setting would be a violation of (first-order) stochastic dominance: Within the classes of low-probability and high-probability prospects, risky prospects in later problems either feature a higher probability of the good outcome (HP) or a higher good outcome (LP). Hence, stochastic dominance requires that, per prospect class, expected-utility maximizers switch their choice at most once and, if so, then from choosing the safe lottery in early problems to choosing the risky lottery in later problems. Across all 280 participants, we find that 29 subjects $(10.4 \%)$ violate this pattern in some way. Running Wilcoxon rank-sum tests concerning the propensity to shift of EU-violators and non-violators, we find the violators shift more often and that the difference is significant at all customary levels. Moreover, the result is robust to conditioning on risky ( $p=0.003, n=254$ ) or cautious shifts $(p=0.001, n=235)$.
} 
Still, we think that it is quite likely that social responsibility plays an independent role besides the wish to conform to the majority. Teasing out the exact effects of social responsibility and conformity would require a different design. This provides an interesting avenue for future research.

Support for the pattern predicted by ERR's model was much more limited. Even in the treatment that gave their theory its best shot, that is, the treatment in which subjects had no information on the majority preference and in which their decisions did not influence others' outcomes, ERR's mechanism could only pick up risky shifts to a notable extent. And in the treatments where both ERR's mechanism and the conformity mechanism could influence choices, the conformity mechanism was seen to predict choice shifts significantly better than ERR's model. The contributions of ERR and Dillenberger and Raymond (2016) point out that non-EU preferences may result in choice shifts in group decisions. Our experimental results suggest that subjects do not systematically have the types of non-EU preferences that result in choice shifts. Instead, the evidence supports the notion that a desire for conformity is a principal driving mechanism behind many choice shifts.

Acknowledgments This paper benefited from the suggestions of audiences at the GATE-LAB workshop (University of Lyon), at the Goethe University Frankfurt, at the University of East Anglia (Norwich), at the ESA World Meeting 2016 (Hebrew University of Jerusalem), and at the SABE/IAREP Conference 2016 (Wageningen University). We thank Joshua Miller for comments. Financial support of the Research Priority Area Behavioral Economics of the University of Amsterdam is gratefully acknowledged.

Open Access This article is distributed under the terms of the Creative Commons Attribution 4.0 International License (http://creativecommons.org/licenses/by/4.0/), which permits unrestricted use, distribution, and reproduction in any medium, provided you give appropriate credit to the original author(s) and the source, provide a link to the Creative Commons license, and indicate if changes were made.

\section{References}

Abdellaoui, M., Bleichrodt, H., L'Haridon, O. (2008). A tractable method to measure utility and loss aversion under prospect theory. Journal of Risk and Uncertainty, 36(3), 245-266.

Abdellaoui, M., Bleichrodt, H., L'Haridon, O., Paraschiv, C. (2011). Experienced versus described uncertainty: Do we need two prospect theory specifications? Management Science, 57(10), 1879-1895.

Abdellaoui, M., Bleichrodt, H., L'Haridon, O. (2013a). Sign-dependence in intertemporal choice. Journal of Risk and Uncertainty, 47(3), 225-253.

Abdellaoui, M., Bleichrodt, H., L'Haridon, O., Paraschiv, C. (2013b). Is there one unifying concept of utility? An experimental comparison of utility under risk and utility over time. Management Science, 59(9), 2153-2169.

Andersen, S., Harrison, G.W., Lau, M.I., Rutström, E.E. (2008). Eliciting risk and time preferences. Econometrica, 76(3), 583-618.

Armantier, O. (2006). Do wealth differences affect fairness considerations? International Economic Review, 47(2), 391-429.

Baillon, A., Bleichrodt, H., Liu, N., Wakker, P.P. (2016). Group decision rules and group rationality under risk. Journal of Risk and Uncertainty, 52(2), 99-116.

Baker, R.J., Laury, S.K., Williams, A.W. (2008). Comparing small-group and individual behavior in lottery-choice experiments. Southern Economic Journal, 75(2), 367-382.

Baltussen, G., Post, G.T., van den Assem, M.J., Wakker, P.P. (2012). Random incentive systems in a dynamic choice experiment. Experimental Economics, 15(3), 418-443.

Baratta, P., \& Preston, M.G. (1948). An experimental study of the auction-value of an uncertain outcome. The American Journal of Psychology, 61(2), 183-193.

Barber, B.M., \& Odean, T. (2000). Too many cooks spoil the profits: Investment club performance. Financial Analysts Journal, 56(1), 17-25. 
Bardsley, N., Cubitt, R., Loomes, G., Moffatt, P., Starmer, C., Sugden, R. (2009). Experimental economics: Rethinking the rules. Princeton: Princeton University Press.

Baron, R.S., \& Roper, G. (1976). Reaffirmation of social comparison views of choice shifts: Averaging and extremity effects in an autokinetic situation. Journal of Personality and Social Psychology, 33(6), 521-530.

Beckman, S.R., DeAngelo, G., Smith, W.J., Wang, N. (2016). Is social choice gender-neutral? Reference dependence and sexual selection in decisions toward risk and inequality. Journal of Risk and Uncertainty, 52(3), 191-211.

Bem, D.J., Kogan, N., Wallach, M.A. (1962). Group influence on individual risk-taking. Journal of Abnormal and Social Psychology, 65, 75-86.

Bem, D.J., Kogan, N., Wallach, M.A. (1964). Diffusion of responsibility and level of risk-taking in groups. Journal of Abnormal and Social Psychology, 68, 263-274.

Bem, D.J., Kogan, N., Wallach, M.A. (1965). Group decision making under risk of aversive consequences. Journal of Personality and Social Psychology, 1(5), 453-460.

Blascovich, J., \& Ginsburg, G.P. (1974). Emergent norms and choice shifts involving risk. Sociometry, $37(2), 205-218$.

Blascovich, J., Ginsburg, G.P., Howe, R.C. (1975a). Blackjack and the risky shift, ii: Monetary stakes. Journal of Experimental Social Psychology, 11(3), 224-232.

Blascovich, J., Ginsburg, G.P., Howe, R.C. (1976). Blackjack, choice shifts in the field. Sociometry, 39(3), 274-276.

Blascovich, J., Ginsburg, G.P., Veach, T.L. (1975b). A pluralistic explanation of choice shifts on the risk dimension. Journal of Personality and Social Psychology, 31(3), 422-429.

Bolle, F. (1990). High reward experiments without high expenditure for the experimenter? Journal of Economic Psychology, 11(2), 157-167.

Bolton, G.E., Ockenfels, A., Stauf, J. (2015). Social responsibility promotes conservative risk behavior. European Economic Review, 74, 109-127.

Bougheas, S., Nieboer, J., Sefton, M. (2013). Risk-taking in social settings: Group and peer effects. Journal of Economic Behavior \& Organization, 92, 274-283.

Bougheas, S., Nieboer, J., Sefton, M. (2015). Risk taking and information aggregation in groups. Journal of Economic Psychology, 51, 34-47.

Brown, R. (1965). Social psychology. New York: Free Press of Glencoe.

Burks, S.V., Carpenter, J.P., Goette, L., Rustichini, A. (2009). Cognitive skills affect economic preferences, strategic behavior, and job attachment. Proceedings of the National Academy of Sciences, 106(19), 7745-7750.

Camerer, C.F., \& Ho, T.-H. (1994). Violations of the betweenness axiom and nonlinearity in probability. Journal of Risk and Uncertainty, 8(2), 167-196.

Casari, M., \& Zhang, J. (2012). How groups reach agreement in risky choices: An experiment. Economic Inquiry, 50(2), 502-515.

Cettolin, E., \& Tausch, F. (2015). Risk taking and risk sharing: Does responsibility matter? Journal of Risk and Uncertainty, 50(3), 229-248.

Cettolin, E., Riedl, A., Tran, G. (2017). Giving in the face of risk. Journal of Risk and Uncertainty, 55(2/3), 95-118.

Charness, G. (2000). Responsibility and effort in an experimental labor market. Journal of Economic Behavior \& Organization, 42, 274-283.

Charness, G., \& Jackson, M.O. (2009). The role of responsibility in strategic risk-taking. Journal of Economic Behavior \& Organization, 69(3), 241-247.

Charness, G., \& Sutter, M. (2012). Groups make better self-interested decisions. Journal of Economic Perspectives, 26(3), 157-176.

Charness, G., Karni, E., Levin, D. (2010). On the conjunction fallacy in probability judgment: New experimental evidence regarding Linda. Games and Economic Behavior, 68(2), 551-556.

Charness, G., Karni, E., Levin, D. (2013). Ambiguity attitudes and social interactions: An experimental investigation. Journal of Risk and Uncertainty, 46(1), 1-25.

Charness, G., Gneezy, U., Halladay, B. (2016). Experimental methods: Pay one or pay all. Journal of Economic Behavior \& Organization, 131, 141-150.

Cialdini, R.B., \& Goldstein, N.J. (2004). Social influence: Compliance and conformity. Annual Review of Psychology, 55, 591-621.

Cohen, M., Jaffray, J.-Y., Said, T. (1987). Experimental comparison of individual behavior under risk and under uncertainty for gains and for losses. Organizational Behavior and Human Decision Processes, $39(1), 1-22$. 
Colombier, N., Denant-Boemonta, L., Lohéac, Y., Masclet, D. (2009). Group and individual risk preferences: A lottery-choice experiment with self-employed and salaried workers. Journal of Economic Behavior \& Organization, 70(3), 470-484.

Cooper, D., \& Rege, M. (2011). Misery loves company: Social regret and social interaction effects in choices under risk and uncertainty. Games and Economic Behavior, 73(1), 91-110.

Cox, J.C., Sadiraj, V., Schmidt, U. (2014). Paradoxes and mechanisms for choice under risk. Experimental Economics, 18(2), 215-250.

Cubitt, R.P., Starmer, C., Sugden, R. (1998). On the validity of the random lottery incentive system. Experimental Economics, 1(2), 115-131.

Davis, J.H., \& Johnson, C.D. (1972). An equiprobability model of risk-taking. Organizational Behavior and Human Performance, 8(1), 159-175.

Davis, J.H., \& Hinsz, V.B. (1982). Current research problems in group performance group dynamics. In Brandstatter, H., Davis, J.H., Stocker-Kreichgauer, G. (Eds.) Group Decision-Making (pp. 1-22). London: Academic Press.

Davis, J.H., Hoppe, R.A., Hornseth, J.P. (1968). Risk-taking: Task, response pattern, and grouping. Organizational Behavior and Human Performance, 3(2), 124-142.

Davis, J.H., Sussmann, N.K.M., Rissman, A.K. (1974). Social decision schemes under risk. Journal of Personality and Social Psychology, 30(2), 248-271.

Dillenberger, D., \& Raymond, C. (2016). Group-shift and the consensus effect. PIER Working Paper No. $16-005$.

Eijkelenboom, G.J., Rohde, I., Vostroknutov, A. (2018). The impact of the degree of responsibility and mutual decision making on choices under risk. Working paper. Maastricht University and University of Trento.

Eliaz, K., Ray, D., Razin, R. (2006). Choice shifts in groups: a decision-theoretic basis. American Economic Review, 96(4), 1321-1332.

Goeree, J.K., \& Yariv, L. (2015). Conformity in the lab. Journal of the Economic Science Association, $1(1), 15-28$.

Gurdal, M., \& Miller, J. (2010). Norms or preferences? A group choice experiment. Unpublished working paper.

Harbaugh, W.T., Krause, K., Vesterlund, L. (2010). The fourfold pattern of risk attitudes in choice and pricing tasks. The Economic Journal, 120(545), 595-611.

Harrison, G.W., \& Swarthout, J.T. (2014). Experimental payment protocols and the bipolar behaviorist. Theory and Decision, 77(3), 423-438.

Harrison, G.W., Lau, M.I., Rutström, E. (2007). Estimating risk attitudes in Denmark: A field experiment. Scandinavian Journal of Economics, 109(2), 341-368.

Harrison, G.W., Lau, M.I., Rutström, E., Tarazona-Gómez, M. (2013). Preferences over social risk. Oxford Economic Papers, 65, 25-46.

Hey, J.D., \& Lee, J. (2005a). Do subjects remember the past? Applied Economics, 37(1), 9-18.

Hey, J.D., \& Lee, J. (2005b). Do subjects separate (or are they sophisticated)? Experimental Economics, $8(3), 233-265$.

Holt, C.A. (1986). Preference reversals and the independence axiom. American Economic Review, 76(3), 508-515.

Isenberg, D.J. (1986). Group polarization: A critical review and meta-analysis. Journal of Personality and Social Psychology, 50(6), 1141-1151.

Kahneman, D., \& Tversky, A. (1979). Prospect theory: An analysis of decision under risk. Econometrica, 47(2), 263-292.

Keck, S., Diecidue, E., Budescu, D.V. (2014). Group decisions under ambiguity: Convergence to neutrality. Journal of Economic Behavior \& Organization, 103, 60-71.

Kocher, M., Sutter, M., Wakolbinger, F. (2014). Social learning in beauty-contest games. Southern Economic Journal, 80(3), 586-613.

Kogan, N., \& Zaleska, M. (1969). Level of risk selected by individuals and groups when deciding for self and for others. Proceedings of the Annual Convention of the American Psychological Association, 4 , $423-424$.

Kőszegi, B., \& Rabin, M. (2007). Reference-dependent risk attitudes. American Economic Review, 97(4), 1047-1073.

Kunreuther, H., \& Pauly, M. (2004). Neglecting disaster: Why don't people insure against large losses? Journal of Risk and Uncertainty, 28(1), 5-21.

Lahno, A.M., \& Serra-Garcia, M. (2015). Peer effects in risk taking: Envy or conformity? Journal of Risk and Uncertainty, 50(1), 73-95. 
Laury, S. (2005). Pay one or pay all: Random selection of one choice for payment. Andrew Young School of Policy Studies Research Paper Series.

Lee, J. (2008). The effect of the background risk in a simple chance improving decision model. Journal of Risk and Uncertainty, 36(1), 19-41.

Myers, D.G. (1978). Polarizing effects of social comparison. Journal of Experimental Social Psychology, 14(6), 554-563.

Myers, D.G., Wojcicki, S.B., Aardema, B.S. (1977). Attitude comparison: Is there ever a band-wagon effect? Journal of Applied Social Psychology, 7(4), 341-347.

Myers, D.G., Bruggink, J.B., Kersting, R.C., Schlosser, B.A. (1980). Does learning others' opinions change one's opinions? Personality and Social Psychology Bulletin, 6(2), 253-260.

Nordhøy, F. (1962). Group interaction in decision-making under risk. Unpublished master thesis, MIT School of Industrial Management.

Pahlke, J., Strasser, S., Vieider, F.M. (2015). Responsibility effects in decision making under risk. Journal of Risk and Uncertainty, 51(2), 125-146.

Prelec, D. (1998). The probability weighting function. Econometrica, 66(3), 497-527.

Pruitt, D.G. (1971). Choice shifts in group discussion: An introductory review. Journal of Personality and Social Psychology, 20(3), 339-360.

Pruitt, D.G., \& Teger, A.I. (1967). Components of group risk taking. Journal of Experimental Social Psychology, 3(2), 189-205.

Pruitt, D.G., \& Teger, A.I. (1969). The risky shift in group betting. Journal of Experimental Social Psychology, 5(2), 115-126.

Savage, L.J. (1954). The foundations of statistics. New York: Wiley.

Schotter, A. (2003). Decision making with naive advice. American Economic Review, 74(2), 196-201.

Schunk, D., \& Betsch, C. (2006). Explaining heterogeneity in utility functions by individual differences in decision modes. Journal of Economic Psychology, 27(3), 386-401.

Sherman, S.J., Wolosin, M.A., Wolosin, R.J., Zajonc, R.B. (1968). Individual and group risk-taking in a two-choice situation. Journal of Experimental Social Psychology, 4(1), 89-106.

Shupp, R.S., \& Williams, A.W. (2008). Risk preference differentials of small groups and individuals. The Economic Journal, 118(525), 258-283.

Sobel, J. (2014). On the relationship between individual and group decisions. Theoretical Economics, 9 , $163-185$

St. Jean, R. (1970). Reformulation of the value hypothesis in group risk taking. Proceedings of the 78th Annual Convention of the American Psychological Association, 5, 339-340.

Starmer, C., \& Sugden, R. (1991). Does the random-lottery incentive system elicit true preferences? An experimental investigation. American Economic Review, 81(4), 971-978.

Stoner, J.F. (1961). A comparison of individual and group decisions involving risk. Unpublished master thesis, MIT School of Industrial Management.

Stoner, J.F. (1968). Risky and cautious shifts in group decisions. Journal of Experimental Social Psychology, 4(4), 442-459.

Sutter, M. (2007). Are teams prone to myopic loss aversion? An experimental study on individual versus team investment behavior. Economics Letters, 97, 128-132.

Sutter, M. (2009). Individual behavior and group membership: Comment. American Economic Review, 99, 2247-2257.

Toubia, O., Johnson, E., Evgeniou, T., Delquié, P. (2012). Dynamic experiments for estimating preferences: An adaptive method of eliciting time and risk parameters. Management Science, 59(3), 613-640.

Tversky, A., \& Kahneman, D. (1981). The framing of decisions and the psychology of choice. Science, 211(4481), 453-458.

Vieider, F.M., Villegas-Palacio, C., Martinsson, P., Mejía, M. (2016). Risk taking for oneself and others: A structural model approach. Economic Inquiry, 54(2), 879-894.

Vinokur, A. (1971). Review and theoretical analysis of the effects of group processes upon individual and group decisions involving risk. Psychological Bulletin, 76(4), 231-250.

von Gaudecker, H.-M., van Soest, A., Wengström, E. (2011). Heterogeneity in risky choice behavior in a broad population. American Economic Review, 101(2), 664-694.

Wakker, P.P. (2001a). Decision-foundations for properties of nonadditive measures: General state spaces or general outcome spaces. Games and Economic Behavior, 50(1), 107-125.

Wakker, P.P. (2001b). Testing and characterizing properties of nonadditive measures through violations of the sure-thing principle. Econometrica, 69(4), 1039-1059.

Wakker, P.P. (2010). Prospect theory: For risk and ambiguity. Cambridge: Cambridge University Press. 